\title{
CICLOS DE FORMAÇÃO HUMANA COM COMPLEXOS DE ESTUDO NAS ESCOLAS ITINERANTES DO PARANÁ*
}

\author{
Marlene Lucia Siebert Sapelli ${ }^{1}$
}

\begin{abstract}
RESUMO: O Movimento dos Trabalhadores Rurais Sem Terra (MST) é resultado de processos de luta pela Reforma Agrária que, desde o início, esteve atrelada a outras lutas, especialmente pela educação. O objetivo desse trabalho é analisar o processo de formulaçáo da proposta dos Ciclos de Formação Humana e a posterior incorporação dos Complexos de Estudo nas escolas itinerantes do Paraná. Produzimos a pesquisa a partir do estudo de bibliografias específicas e de análise documental. Na primeira parte, explicitamos a concepção de alguns autores acerca da natureza e da especificidade da escola capitalista, e analisamos a formulação da proposta dos Ciclos de Formação Humana e a incorporação dos Complexos de Estudo. $\mathrm{Na}$ segunda parte, apresentamos elementos da avaliaçáo dos quatro primeiros anos de implementação da proposta.
\end{abstract}

Palavras-chave: Movimentos dos Trabalhadores Rurais Sem-Terra. Ciclos de formação humana. Complexos de estudo. Escolas itinerantes. Paraná.

\section{HUMAN FORMATION CYCLES WITH STUDY COMPLEXES, IN ITINERANT SCHOOLS OF PARANA}

ABSTRACT: The Landless Rural Workers Movement is the result of the struggle processes for Agrarian Reform, and from the outset, this struggle had been linked to other struggles, especially for education. The objective of this work is to analyze the proposal formulation process of the Human Formation Cycles, and later incorporation of Study Complexes, in the itinerant schools of Paraná. We produced the research from the study of specific bibliographies and documentary analysis. In the first part, we explained the conception of some authors about the nature and the specificity of the capitalist school, and we analyzed the formulation of the Human Cycle, and the incorporation of the Study

\footnotetext{
*Este artigo é resultado do Projeto de Pesquisa Continuada aprovado pela Pró-Reitoria de Pesquisa da Universidade Estadual do Centro-Oeste (UNICENTRO), Guarapuava, PR, executado de 2015 a 2017, e do projeto intitulado "Análise do processo de implementação, dos fundamentos teórico-metodológicos e da origem histórica da proposta curricular dos 'Complexos de Estudo"', executado em 2014 e 2015, parcialmente financiado pelo Conselho Nacional de Desenvolvimento Científico e Tecnológico (CNPq), por meio da Chamada no 43/2013 - Ciências Humanas, Sociais e Sociais Aplicadas. ${ }^{1}$ Universidade Estadual do Centro-Oeste, Departamento de Pedagogia - Guarapuava (PR), Brasil. E-mail marlenesapelli@gmail.com DOI: $10.1590 / E S 0101-73302017180548$
} 
Complexes. In the second part, we presented the evaluation elements of the first four years of the proposal implementation.

Keywords: Landless Rural Workers Movements. Human formation cycles. Study complexes. Itinerant schools. Parana.

\section{LES CYCLES DE FORMATION HUMAINE AVEC DES COMPLEXES EN ÉTUdES DES ÉCOLES ITINÉRANTES AU PARANÁ}

RÉSUMÉ: Le Mouvement des Trabalhadores Rurais Sem Terra (Travailleurs Ruraux Sans Terre) est le résultat de processus de lutte pour la Réforme Agraire et depuis le début, ce combat a été liée à d'autres combats, en particulier pour l'éducation. Le but de cette étude est d'analyser le processus de formulation de la proposition de Cycles de Formation Humaine et l'incorporation ultérieure de complexes d'Études, dans les écoles itinérantes du Paraná. Nous produisons la recherche à partir de l'étude des bibliographies spécifiques et analyse documentaire. Dans la première partie, nous soulignons la conception de certains auteurs sur la nature et la spécificité de l'école capitaliste et nous analysons le libellé de la proposition des Cycles de Formation Humaine et l'incorporation des Complexes d'Étude et la deuxième partie, nous présentons des éléments de l'évaluation des quatre premières années de la mise en œuvre de la proposition.

Mots-clé: Mouvement des Travailleurs Ruraux Sans Terre. Cycles de formation humaine. Complexes d'étude. Écoles itinérantes. Paraná.

\section{Introdução}

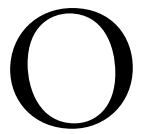

Movimento dos Trabalhadores Rurais Sem Terra (MST), desde os anos 1980, tem forjado no contexto da luta de classes a luta pela Reforma Agrária e, nela, tem empenhado esforços para construir seu projeto educacional. Esse artigo teve como objetivo analisar parte desse percurso - 2003 a 2016 —, buscando compreender a formulação da proposta dos ciclos de formação humana e a incorporação dos complexos de estudo nas escolas itinerantes ${ }^{1}$ do Paraná, avaliando os quatro primeiros anos da incorporação dos últimos elementos à mesma. A pesquisa foi realizada a partir do estudo de bibliografia relacionada às questóes indicadas, de autores clássicos, mas também de pesquisas recentes que se propuseram a analisar e registrar o processo educacional do MST do Paraná (MST/PR) e análise de documentos nos quais está registrado o referido processo de implementação. 


\section{A natureza e a especificidade da escola capitalista: a necessidade do enfrentamento}

A escola capitalista tem cumprido importante papel na formação da classe trabalhadora na perspectiva de submetê-la aos interesses do capital, contribuindo para forjar sua representação simbólica, sua força de trabalho, suas relaçôes, suas capacidades e seus valores de forma alienada. Vários autores têm se dedicado a explicitar e a desmascarar o caráter de classe desse projeto da burguesia.

Snyders (2005) entende que a burguesia constitui a escola de classe com o objetivo de "educar a jovem geração de operários e de camponeses na esperança de formar simultaneamente servidores úteis, suscetíveis de lhe proporcionar benefícios e lacaios obedientes que não perturbem a sua quietude e a sua ociosidade" (SNYDERS, 2005, p. 31). O autor entende que a burguesia, para mascarar suas intençóes, apresenta o projeto de uma escola apolítica, que está acima e alheia à luta de classes, que estaria a serviço da sociedade toda e contribuiria para o desenvolvimento das crianças. Analisa, também, que se trata de uma hipocrisia burguesa que tem a intenção de iludir as massas. Para se contrapor à escola burguesa, o autor entende que a mesma é necessária, mas que só realizará plenamente seu papel numa sociedade renovada, pois náo tem autonomia no interior da sociedade capitalista e só avança para escola progressista com a pressão do proletariado. Considera que há tarefas pedagógicas possíveis e necessárias na sociedade atual e indica que a escola deve se movimentar no sentido de apoiar o que há de positivo nas crianças da classe operária, ajudando-as a ultrapassar seus limites, proporcionando-lhes uma cultura mais real, tornando-se uma escola do atual, que possibilite que a vida da classe trabalhadora faça parte da escola, que esteja conectada com o movimento social e que ensine a cooperação e a solidariedade.

Mészáros (2005) indica que a escola capitalista tem a tarefa de "fornecer conhecimentos e o pessoal necessário à maquinaria produtiva em expansão do sistema capitalista, mas também gerar e transmitir um quadro de valores que legitima os interesses da classe dominante" (MÉSZÁROS, 2005, p. 15). Assim, a função da escola é educar para a conformação. Uma das estratégias do capital é, por meio da educação, fazer com que os indivíduos internalizem como natural a posição que lhes foi atribuída na hierarquia social, bem como as formas corretas de conduta que lhe cabem, ou seja, devem ser induzidos a uma aceitação dos princípios orientadores da sociedade capitalista. Propóe, assim, para se contrapor à escola capitalista, que se faça uma mudança radical na forma de internalização, que se desate a educação formal do seu tegumento da lógica do capital e que a escola assuma o papel de contribuir para elaborar estratégias de automudança consciente dos indivíduos, tornando-os capazes de atuar como produtores livremente associados no processo de mudança social. 
Na mesma linha de entendimento, Suchodolski (1976), pautado nos escritos de Marx e Engels, ratifica o caráter de classe da escola capitalista e compreende, como Snyders, que o sistema de ensino é um instrumento dos interesses da classe dominante, que a apresenta sustentada no discurso acerca da liberdade e das possibilidades de desenvolvimento camuflando seu real objetivo. A burguesia, segundo o autor, atribui à escola o papel de resolver as mazelas sociais e entende que a escola capitalista reforça a desigualdade social, sufocando o impulso revolucionário das massas. Para o autor a escola contra-hegemônica deve proporcionar uma ligação estreita entre educação e trabalho — educação politécnica —, na perspectiva de superar a dicotomia entre trabalho intelectual e manual e de possibilitar o pleno desenvolvimento das capacidades humanas; também defende que o ensino deve estar intimamente ligado à atividade revolucionária da classe trabalhadora. Essas ligações são necessárias no processo de formação dos indivíduos, para que sejam preparados para realizar suas tarefas históricas no processo de transformação da sociedade.

Reforçando o entendimento dos autores anteriores, Bourdieu e Passeron (2008) entendem que o papel da escola é de legitimar a ordem social, reproduzindo no seu interior o sistema simbólico hegemônico da sociedade. Os autores consideram esse sistema um instrumento estruturado e estruturante de conhecimento e de comunicação, que representa uma concepção hegemônica de um determinado tempo e espaço - e é essa concepção hegemônica que torna possível o consenso acerca do sistema. Para os autores, os símbolos são instrumentos de integração social e tornam possível a construção do consenso que contribui para a reprodução da ordem social; portanto, da legitimação da ordem estabelecida. O que se obtém com o poder simbólico, segundo eles, equivale àquilo que se alcança pela força física e econômica (BOURDIEU; PASSERON, 2008). É difícil identificar, na obra dos autores, proposição de outra escola. Apesar disso, reconhecem que as coisas não são eternas (Idem). Em 1999, três anos antes de falecer, numa entrevista concedida a Loyola, Bourdieu expressou sua crença na necessidade de se construir novas formas de luta social, reconhecendo inclusive a possibilidade de a escola ser um lugar de mudança, como no trecho que segue

O mundo da cultura está repleto de nichos [...]. Por estranho que pareça, acho que o futuro está nessa lógica do nicho. [...]. Há públicos potenciais [...] O sistema escolar continua sendo um dos nichos possíveis da concorrência do privado: ele oferece a dedicação, pessoas que acreditam, além de recursos, certamente náo são muito grandes, mas que permitem que se façam coisas. (LOYOLA, 2002, p. 47).

Arroyo (1999, p. 15) corrobora para esse entendimento ao afirmar que há um isomorfismo entre a organização da escola e o mundo da produção capitalista, que se caracteriza pela "consolidação de um processo de internalização como 
justa e necessária à exploração e à dominação". Entende que o sistema escolar é um microcosmo no qual também se aprendem os papéis sociais. Podemos considerar como práticas executadas com esse fim:

- $\quad$ estabelecimento de regras sem sentido para treinar a obediência inquestionável;

- controle de assiduidade;

- avaliação classificatória;

- meritocracia por superaçáo de desafios série por série;

- horários escolares similares ao das empresas;

- $\quad$ proibição de trazer a vida privada para a escola, a não ser em momentos autorizados;

- hierarquização das relaçóes;

- gestão gerencial;

- distanciamento da vida, dentre outras.

$\mathrm{O}$ autor entende que, para se contrapor a essa vinculaçáo imediatista entre trabalho-educação-escola, é necessário repensar a teoria pedagógica, a didática, os currículos e a organização escolar e recolocar a centralidade educativa da materialidade e das relaçôes sociais imperantes na escola, na perspectiva de construir relaçóes mais democráticas e inclusivas e de tornar a educação uma açáo-intervenção política e cultural que mexa com as aspiraçóes, com os valores e com os pensamentos dos indivíduos, tendo como horizonte a emancipação humana.

Poderíamos seguir indicando vários outros autores que ratificariam o entendimento dos aqui apresentados, mas esses são suficientes para nossa problematização sobre a natureza e a especificidade da escola. Historicamente, a escola burguesa, capitalista, foi engendrada para atender aos interesses da classe dominante e para contribuir para submeter a ela a classe trabalhadora. Porém, tal constatação não é tão explícita, pois há um esforço em apresentá-la de forma ideológica, mascarando seu papel. No decorrer da sua trajetória, muitas reformas foram feitas, mas nenhuma mudança estrutural. Ora as reformas incidem sobre a metodologia, ora sobre o conteúdo, ora sobre a formação dos educadores, ora sobre a avaliação, ora sobre a organização, mas sempre como meras reformulaçōes pontuais. Isso é intencional, pois não se pode perder o controle do conteúdo e da forma da escola, tal como foi proposta para servir ao capital. Esse entendimento não está restrito à educação básica, mas também abrange o ensino superior e a pós-graduação.

Poucas são as iniciativas consolidadas para destruir o projeto da escola capitalista e/ou para construir um projeto contra-hegemônico. O MST é um dos poucos coletivos que, historicamente, tem se desafiado a enfrentar tal questão. 
Tem forjado, no interior da luta de classes, na luta pela terra, uma escola que, insistentemente, tenta romper com a forma e com o conteúdo da sua expressão capitalista, mas que tem encontrado resistências e articulaçóes para impedir que o façam, tanto internas como externas. O enfrentamento à forma e ao conteúdo da escola capitalista é uma necessidade no processo de formação da classe trabalhadora enquanto classe para $s i^{2}$, uma vez que, ao realizar suas várias funções, com perspectiva de futuro e de rompimento com o atual status quo, pode representar instrumento de luta dessa classe. Vemos na sequência como se dá esse processo nas escolas itinerantes do Paraná, vinculadas ao Movimento.

\section{0 forjar da proposta de educação do MST: ciclos de formação humana com complexos de estudo}

O MST é um movimento social, engendrado a partir de conflitos provocados, em vários momentos e de diferentes formas, ao se contrapor à concentração da propriedade da terra e à expulsão dos trabalhadores que a tinham como meio de produção. Isso ocorreu em todo o território nacional e, no Paraná, está in timamente relacionado com a construção das usinas hidrelétricas, com a imposição do latifúndio forjado sob o sangue dos trabalhadores, com o papel do Estado, enquanto espaço de domínio da classe dominante. $\mathrm{O}$ mesmo processo que tem forjado esse movimento, o faz em relação à proposta de escola. Desde as lutas dos anos de 1970 e 1980, que deram origem ao MST, havia uma preocupação em buscar elementos de sustentaçáo para uma proposta de escola que se contrapusesse ao modelo capitalista, ou seja, que pudesse construir no seu interior relaçóes horizontalizadas que potencializassem a auto-organização dos estudantes, que vinculasse os conteúdos da ciência, da filosofia e da arte com a vida, e que tivesse perspectiva de futuro, que formasse lutadores e construtores com consciência crítica acerca da sociedade, uma escola intimamente ligada à luta.

E nesse caminho, em 2003, foram criadas oficialmente, no Paraná, as escolas itinerantes, ou seja, de acampamento, por meio do Parecer $n^{\circ} 1.012$, de 8 de dezembro de 2003, e da Resolução no 614, de 17 de fevereiro de 2004. De lá até os dias de hoje foram criadas 20 dessas escolas, permanecendo em funcionamento, em 2017, 12 escolas (MARIANO, 2016). A partir de 2005, o coletivo estadual de educadores do MST das escolas itinerantes construiu a proposta dos ciclos de formação humana que, depois de um longo processo, teve autorização para ser implementada como experimento, por meio do Parecer do CEE/PR no 117, de 11 de fevereiro 2010, e da Resolução no 3.922/2010, por cinco anos (SAPELLI, 2013).

A proposta dos ciclos de formação humana está pautada nos princípios pedagógicos e filosóficos do Movimento e expressa o acúmulo de aprendizagens ocorrido na trajetória da escola, a partir das experiências realizadas em outros estados brasileiros. Além disso, há a adoção de um currículo contínuo, sem reprova- 
ção, com atendimento em classes intermediárias ao final de cada ciclo. O conjunto da educação básica é organizado em cinco ciclos:

1. o da educação infantil ( 4 e 5 anos);

2. o ciclo I (6,7 e 8 anos);

3. o ciclo II (9,10,11 anos);

4. o ciclo III (12,13,14 anos); e

5. o ciclo único (ensino médio).

A referência para a apresentação das concepçôes de desenvolvimento, de aprendizagem, é Vygotsky ${ }^{3}$ que os compreende como processos distintos, mas interdependentes, e afirma que o desenvolvimento das funçóes psicológicas superiores é um processo complexo marcado por saltos qualitativos que ocorrem em três momentos: da filogênese (ao longo da história da espécie), da ontogênese (como desenvolvimento individual) e da sociogênese (como resultado da interação do meio físico e social). Vygotsky (2007) entende que o desenvolvimento tem como aspecto necessário a aprendizagem e a melhor é aquela que se antecipa ao desenvolvimento, ou seja, ela póe em movimento vários processos de desenvolvimento e cria zonas de desenvolvimento proximal. Entende o autor que o processo de interiorização das funções psicológicas superiores é histórico, portanto, as estruturas de percepção, atenção voluntária, memória, linguagem e outras assumem diferentes formas, de acordo com o contexto histórico cultural. O "aprendizado deve ser combinado de alguma maneira com o nível de desenvolvimento da criança” (VYGOTSKY, 2007, p. 95). Isso não nos remete à compreensão de que o desenvolvimento seja pré-requisito para a aprendizagem, mas que são processos interdependentes. O nível de desenvolvimento real define funções que já amadureceram, mas não aquelas que se apresentam em estágio embrionário. A partir dessa constatação, Vygotsky (2007) afirma que o "nível de desenvolvimento real caracteriza o desenvolvimento mental prospectivamente" (VYGOTSKY, 2007, p. 98). Para ele, "o estado mental da criança só pode ser determinado se forem revelados os dois níveis" (VYGOTSKY, 2007, p. 98). A partir desse entendimento, o autor defende que "o aprendizado orientado para os níveis de desenvolvimento que já foram atingidos é ineficaz do ponto de vista do desenvolvimento global" (VYGOTSKY, 2007, p. 102). Entende ele que os processos de aprendizagem e desenvolvimento não ocorrem no mesmo ritmo, considera que o processo de desenvolvimento é mais lento.

Nessa proposta também há a adoção da área como princípio metodológico e a distribuição da carga horária de forma quase igualitária entre as disciplinas, caracterizando-se como proposta disciplinar. As atividades são realizadas em um agrupamento de referência, mas também por reagrupamento, considerando as 
necessidades e potencialidades dos educandos. A escola se organiza em diferentes tempos educativos (formatura, mística, leitura, trabalho, reunião, dentre outros). Os registros das avaliaçóes ocorrem em um caderno e em uma pasta de acompanhamento, que são utilizados para construir o Parecer Descritivo. Ao final de cada etapa, são realizados conselhos participativos (envolvem processos de avaliaçáo e autoavaliação). A gestão proposta é a democrática, na perspectiva de promover vivências de relações horizontalizadas e de coletividade, com ampla participação da comunidade na qual cada escola se insere (GOVERNO DO PARANÁ, 2009, 2013).

Num primeiro momento da implementaçáo da proposta dos ciclos de formação humana, a referência pedagógica era Paulo Freire e os temas geradores. A adoção da metodologia proposta por Freire está intimamente relacionada à preocupaçáo que o Movimento tem em construir processos que contribuam para a constituiçáo da consciência crítica da vida e em descodificar a realidade. Para Freire (2005 apud SAPELLI, 2013), esse processo se dá da síncrese à síntese, passando pela análise. $\mathrm{O}$ autor entendia que era preciso conhecer para compreender e compreender para transformar. A consciência crítica, segundo ele, caracteriza-se:

- $\quad$ pelo anseio de profundidade de análise de problemas;

- pelo reconhecimento da mutabilidade da realidade;

- pela substituição de situaçôes ou explicaçóes mágicas por princípios autênticos de causalidade;

- pela indagação permanente.

Em relação aos temas geradores, Freire (apud SAPELLI, 2013, p. 230) considerava que eram necessários dois critérios para defini-los: o tema gerador "precisa ser algo 'reconhecido' pelos sujeitos e não estranho a eles e deve ser simples, mas oferecer possibilidades plurais de análise na sua descodificação, devem abrir leque temático".

Muitos temas foram utilizados nas escolas, como o "uso de agrotóxicos e seus malefícios; organicidade da escola; questóes ambientais (lixo, água), agroecologia, agricultura familiar, higiene, sexualidade, qualidade de vida, sementes e outros" (SAPELLI, 2013, p. 228). Segundo a autora, a escolha dos temas, nas escolas itinerantes em questão, era motivada pelas tensóes vividas nos acampamentos. Na sua pesquisa, a autora constatou que as escolas eram menos freireanas do que se anunciava, isso, principalmente, em decorrência da falta de conhecimento.

A transposição da proposta freireana para as escolas itinerantes, da forma como foi feita, provocou certo esvaziamento de conteúdos no processo pedagógico das mesmas. Entre 2010 e 2012, o setor de educação do MST/PR promoveu vários encontros para avaliar a proposta em andamento (ciclos de formaçáo 
humana) e para propor estratégias que contribuíssem para se avançar na construção da mesma. Com o acúmulo de conhecimento que o Movimento já tinha e, em parceria com alguns pesquisadores de universidades e do próprio Movimento, houve a reestruturação da proposta e a incorporação dos complexos de estudo (MST, 2014).

Esse processo de três anos possibilitou a construção de uma metodologia para compor um Plano de Estudos, a formação continuada dos educadores e comunidades envolvidas e a implementação gradativa dos elementos novos da proposta nas escolas. A assessoria principal foi de Roseli Salete Caldart (MST) e de Luiz Carlos de Freitas (UNICAMP). Para os pesquisadores das universidades, o processo representou uma aprendizagem relevante na área de currículo, que, desde os anos 1980, não tem recebido a atenção que precisa ter no âmbito acadêmico (basta verificar quantos cursos de licenciatura possuem disciplina específica para tratar dessa questão ou para indagar os egressos desses cursos sobre o tempo destinado a discutir método e conteúdos a serem trabalhados na educação básica), bem como sobre o papel da escola na luta de classes.

A referência para o avanço na discussão da proposta curricular do MST nas escolas itinerantes do Paraná é a experiência soviética, o que não é fato novo na trajetória do setor de educação do Movimento. Segundo Caldart ${ }^{4}$, já nos anos 1980, o Movimento estudava a obra de Pistrak intitulada Fundamentos da escola do trabatho, que recém havia sido publicada no Brasil. Naquele momento, o que chamou a atenção do grupo foram três questôes centrais da obra: a vida, auto-organização dos estudantes e o trabalho. Como não havia outras referências, ficou difícil utilizá-la. No grupo também existia o estudo das obras de Paulo Freire que, naquele momento, fornecia respostas às necessidades do Movimento: aproximar a escola da vida e formar criticamente. Por isso, a ênfase nos primeiros anos foi o tema gerador. Naquele mesmo período, o professor Luiz Carlos de Freitas, da Unicamp 5 , visitou a Uniáo das Repúblicas Socialistas Soviéticas (URSS) para estudar Pistrak.

Nos anos 2000, Freitas foi visitar o Instituto Josué de Castro (espaço de formação vinculado ao MST), em Veranópolis, RS, e pôde constatar que vários elementos da pedagogia soviética estavam sendo experimentados. Foi assim que Freitas passou a contribuir com a avaliação e avanço da proposta do MST. Dessa parceria, e junto à Editora Expressão Popular, teve início também a tradução e publicação de outras obras: A escola comuna, de Pistrak (2009); Rumo ao politecnismo, de Shulgin (2013); e A construção da pedagogia socialista, de Krupskaya (2017).

Na URSS, a proposta dos complexos foi produzida no contexto da Revolução de 1917. Logo depois da Revolução, foram criadas escolas experimentais, as escolas-comuna que tinham a tarefa de construir e implementar a nova pedagogia. Foi instituída uma comissão, coordenada por Pistrak, para elaborar os programas. Houve dificuldades para implementar a proposta, que tinha como elementos centrais o enfoque marxista, o ensino pelo e para o trabalho, a ligação 
com a atualidade e a auto-organização dos estudantes. A proposta dos complexos não se limitava a ser apenas uma metodologia, mas uma forma de organização do programa de ensino, que exigia:

- $\quad$ seleção dos temas dos complexos;

- $\quad$ estudo de cada tema;

- a organização do ensino segundo o sistema dos complexos; e

- a organização do trabalho dos estudantes no sistema de complexos (SAPELLI, 2013).

No período de 2010 a 2012, várias etapas fizeram parte do processo, algumas de forma concomitante:

- momentos de estudo sobre a proposta soviética e do MST;

- $\quad$ avaliação da proposta do MST, forjada desde os anos 1980;

- elaboração dos inventários da realidade na qual estão inseridas as escolas itinerantes;

- exercícios de elaboração de conteúdos e objetivos (formativos e de ensino), de relação entre objetivos e porçôes da realidade/categorias da prática;

- $\quad$ sistematização do Plano de Estudos;

- formaçáo continuada dos coletivos das escolas;

- definição das matrizes pedagógicas;

- discussões acerca da forma da escola.

Segundo Sapelli (2013), houve muitas dificuldades nesse processo de elaboração do Plano de Estudos, relacionadas:

- ao financiamento dos encontros;

- à rotatividade dos especialistas das disciplinas;

- à dificuldade de recriar a proposta soviética no âmbito das escolas itinerantes;

- à articulação de conteúdos das disciplinas com a vida;

- à distância dos encontros para a elaboração da proposta.

Mesmo sem o Plano de Estudos concluído, o que aconteceu só em 2013, vários elementos novos/reconfigurados da proposta foram exercitados antes desse período: 
- as escolas construíram os inventários da realidade, explicitando as condiçóes concretas de vida no entorno das mesmas, o que possibilitou a identificação das categorias da prática/porçôes da realidade que movimentariam cada complexo de estudo;

- introduziram nos planejamentos os objetivos formativos, o que provocou uma reflexão profunda sobre a concepção de educação como processo de formação humana em todas as suas dimensóes;

- houve a criação dos Núcleos Setoriais nas escolas, o que potencializou processos já existentes de auto-organização dos estudantes;

- elegeram-se as porçóes da realidade/categorias da prática como articuladoras dos demais elementos do complexo e, portanto, da própria interdisciplinaridade, levou à exigência de planejamento coletivo, o que potencializou práticas de coletividade, tanto no estudo como na construção de proposição e na execução de açóes.

Em 2013, o Plano de Estudos (para os anos finais do ensino fundamental), na sua primeira versão, foi publicado, composto por: uma parte introdutória, na qual se apresenta a concepção de educação e de matriz formativa; as matrizes formativas da vida e decorrentes dela, do trabalho, da luta social, da organização coletiva, da cultura e da história; orientaçóes gerais sobre a forma escolar (a funçấo pedagógica do meio, a organização política da escola, os tempos da escola, aspectos metodológicos específicos, sequenciamento e duração dos complexos, o processo de avaliaçáo). Na segunda parte, no documento é apresentado o detalhamento do Plano de Estudos por ano. Em cada ano são apresentados os objetivos formativos e o conjunto dos complexos propostos para cada semestre. Em cada complexo sáo indicados os seguintes elementos: porção da realidade/categoria da prática; disciplinas envolvidas; justificativa; objetivos de ensino; pré-requisitos e êxitos esperados. A parte de metodologia e de avaliação fica em aberto para construção coletiva nas escolas (MST, 2013). O Plano de Estudo traz a proposta para os anos finais do ensino fundamental, mas não representa uma cartilha de orientaçóes a serem obrigatoriamente seguidas. A forma como o trabalho é encaminhado possibilita a reconstruçáo do que está proposto no documento, em cada escola, a partir do inventário da realidade. $\mathrm{O}$ fato de o documento apresentar apenas a proposta para os anos finais exige que as escolas, que adotam a proposta, construam a parte da educaçáo infantil, dos anos iniciais do ensino fundamental e do ensino médio, a partir dos elementos apresentados na primeira parte do documento. Essa construçáo tem exigido um processo de planejamento coletivo e permanente, bem como um profundo conhecimento da realidade, buscando superar a fragmentação muitas vezes imposta pelo currículo disciplinar.

Desde 2013, as escolas itinerantes vinculadas ao MST/PR vem, coletivamente, realizando um esforço para introduzir os elementos novos/reconfigura- 
dos, bem como para potencializar os elementos estruturantes, presentes desde os anos 1980 na sua proposta de educação. De lá para cá, as escolas têm se organizado para planejar utilizando o Plano de Estudos como referência. O setor estadual de educação do MST/PR também tem promovido a formação dos professores em parceria, principalmente, com a Universidade Estadual do Centro-Oeste (UNICENTRO - Guarapuava, PR), com a Universidade Federal da Fronteira Sul (UFFS - Laranjeiras do Sul, PR) e com a Universidade Estadual do Oeste do Paraná (UNIOESTE - Cascavel, PR). O objetivo é subsidiar o trabalho nas escolas, a partir da adoção dos ciclos de formação humana com complexos de estudo, intercalando momentos de estudo dos fundamentos da proposta, de orientaçáo para os encaminhamentos, da troca de experiências e de exercícios de planejamento coletivos. Além disso, há uma preocupação com a sistematização da trajetória da educação do MST. Assim, além da mudança na escola, da formação continuada, houve a publicação de vários materiais, inclusive registrando essa fase de incorporaçáo dos complexos de estudo à proposta educacional do MST/PR (isso foi feito na obra Caminhos para a transformação da escola 3: organização do trabalho pedagógico nas escolas do campo - ensaio sobre complexos de estudo, organizada por Sapelli et al., 2015).

Apresentamos uma análise do processo, indicando avanços, dificuldades e necessidades do Movimento no processo de avaliação, reconstrução e implementação dos elementos novos/reconfigurados da proposta.

\section{Avaliando o processo}

Depois de quatro anos do início da implementação mais completa da proposta dos ciclos de formação com complexos de estudo, já é possível indicar alguns aspectos que explicitam os avanços, as dificuldades e as atuais necessidades ${ }^{6}$ para continuar esse processo. A primeira constatação é no sentido de entender que não há muitas diferenças entre o que já havia sido produzido pelo Movimento desde os anos 1980 e o que foi incorporado a partir da construção do novo Plano de Estudos. O que aconteceu foi um aprofundamento dos estudos acerca de autores da pedagogia socialista, especialmente, Pistrak, Shulgin e Krupskaya, e da concepção marxista de educação. Com isso, alguns elementos foram potencializados:

- a construçáo do planejamento de ensino em conexão com a vida;

- o exercício de práticas de auto-organização dos estudantes, buscando horizontalizar as relaçóes humanas na escola;

- a concepção de educação como processo de formação humana e como instrumento de luta;

- a educação pelo trabalho e para o trabalho, especialmente considerando o trabalho socialmente necessário. 
Apesar do limite indicado pelas escolas no que se refere à potencialização desses elementos, as práticas já realizadas foram significativas para gerar uma mudança importante na organização do trabalho pedagógico. Exemplo disso é a realização cada vez mais exigente do inventário da realidade que envolve as escolas em questão, o que tem contribuído para explicitar as contradiçóes e potencialidades desse contexto. Igualmente importante tem sido a ampliação da participação dos estudantes no âmbito da tomada de decisóes, na implementação das mesmas e nos processos de formação. Isso impacta diretamente na formação dos militantes, bem como nos processos de aprendizagem e desenvolvimento e nas relaçóes entre os sujeitos envolvidos nesses processos.

Os maiores limites indicados pelas escolas, em relação a esses elementos, referem-se ao trabalho socialmente necessário. Ainda há a necessidade do aprofundamento teórico para se compreender como a escola se (re)organiza para alterar sua estrutura, abrindo-se às necessidades da comunidade e como o ensino pode contribuir para a realização do trabalho socialmente necessário e vice-versa.

A construçáo do Plano de Estudos, bem como o período posterior de implementação, colocou o grupo envolvido num processo muito interessante de formaçáo continuada, que exigiu muita organização do Movimento e das universidades parceiras, busca de financiamento e planejamento. As formaçóes se deram em vários momentos, desde 2013, em âmbito local (portanto, nas escolas e na rede das escolas envolvidas) e de forma centralizada (em Lerroville/Londrina, em Cascavel, em Guarapuava, em Medianeira, em Curitiba, dentre outras localidades), envolvendo as equipes de coordenação das escolas, os educadores, líderes das comunidades, educandos e o setor estadual de educação do MST/PR. Essas açóes explicitam a necessidade de intensificar a relação entre os processos de construção curricular e de formação de professores. Houve dificuldades para financiar um processo mais constante de formação, o que indica a incapacidade e o desinteresse do Estado para promover ações de mudança efetiva da escola, de construção de propostas curriculares contra-hegemônicas, de açôes de formação continuada vinculadas à perspectiva crítica.

A preocupação em definir conteúdos, por semestre, para cada ano escolar, colocou a discussáo sobre o conhecimento em pauta. Houve dificuldades para se definir conteúdos necessários para cada ano, critérios para escolha e definição de prioridades. Com isso, a problemática do método ficou enfatizada, pois a escolha dos conteúdos está intimamente relacionada à definição do método que representa a forma como a realidade é apreendida. Na proposta em questão, os conteúdos escolares — ou seja, o saber — não podem afastar-se da realidade. Nesse debate, aflorou a necessária diferenciação, mas também a articulação entre ciência e saber. Wachovicz (1995) entende que a ciência exige que a inteligência percorra um determinado caminho para apreender a realidade e o saber é resultado do caminho que percorremos para nos apropriarmos 
daquilo que foi descoberto e sistematizado, portanto, patrimônio científico e cultural da humanidade. Isso nos coloca diante dos métodos científico e didático. A autora, nesse sentido, indica que "a forma pela qual se apresenta a realidade à inteligência deve abarcar uma totalidade para que o saber tenha um significado completo" (WACHOVICZ, 1995, p. 22).

Outro aspecto importante a se considerar nessa avaliação é acerca da produção acadêmica. O processo realizado pelo MST/PR foi importante para o avanço da teoria pedagógica, para criar demandas aos pesquisadores. Muitos escritos foram produzidos: trabalhos de conclusão de curso de graduação e especializaçóes, dissertaçóes, teses, artigos, ou seja, muitas investigações, reflexôes foram construídas acerca de currículo, educação e movimentos sociais, pedagogia socialista, planejamento, dentre outras questôes. Limitamo-nos aqui a indicar algumas dissertaçóes e teses produzidas que tratam diretamente do processo realizado pelas escolas itinerantes: Sapelli/tese (2013); Savi/dissertação (2014); Bahniuk/tese (2015), Mariano/dissertação (2016), Ritter/tese (2016) e Leite/dissertação (2017). Todos os pesquisadores, de alguma forma, participaram/participam da construção/implementação da proposta.

Observar esses dois primeiros aspectos exige que reconheçamos que o MST tem criado demandas permanentes para as universidades, que não se vinculam a elas, institucionalmente, mas, em geral, por meio de pesquisadores e extensionistas comprometidos com a educação da classe trabalhadora.

O processo realizado pelo MST - de construção e implementação de proposta curricular - tem servido de referência para outros estados brasileiros. A publicação da obra Caminhos para a transformação da escola 3: organização do trabalho pedagógico nas escolas do campo - ensaio sobre complexos de estudo, já citada, contribuiu para a divulgação da experiência. $\mathrm{O}$ grupo envolvido também tem apresentado seus relatos em vários eventos da área de educação, em diferentes estados brasileiros.

Houve muitas dificuldades nessa trajetória. Uma delas diz respeito às condiçôes materiais das escolas: precariedade nas bibliotecas, falta de materiais de apoio, falta de espaços para práticas esportivas, ausência de laboratórios, dentre outras. O Estado, usando da "legalidade" em relação à ocupação da terra, desresponsabiliza-se pelas questóes estruturais, garantindo o mínimo nessa questão.

Outra dificuldade se refere aos professores. Nessa questão, podemos apontar vários elementos. Um deles é a rotatividade dos professores contratados pelo Estado para atuar nas escolas itinerantes. Essa rotatividade dificulta a apreensão dos fundamentos da proposta e a construção de Planos de Trabalho docente que possam acumular a experiência para qualificá-la, ano após ano. Outro aspecto é a própria formação de professores nas universidades. Ocorre que, em geral, a formação feita pelas universidades acolhe a agenda do capital (TRICHES, 2016), 
contribuindo para a formação de profissionais não críticos, com apropriação precária de conhecimento, numa perspectiva pragmática. Esse perfil dificulta a organizaçáo de um trabalho crítico na escola e consistente no sentido de garantir o acesso ao conhecimento. Outra dificuldade que, de certa forma, é decorrente ainda desse perfil, é a quase incapacidade de construir o planejamento de forma coletiva, propondo práticas de interdisciplinaridade a partir das categorias da prática/porções da realidade. Não desconsideramos aqui que a dificuldade de planejamento coletivo também está relacionada a outros dois fatores: precarização dos contratos e das condiçóes de trabalho dos professores que impóe a eles o trabalho em várias escolas para compor sua carga horária de aulas semanais e o medo de expor suas fragilidades ao realizar o trabalho coletivo.

Atualmente, a maior dificuldade do MST para prosseguir no processo é o ataque que a escola itinerante vem sofrendo por parte do governo estadual (PSDB), fato que tem dificultado a permanência dos integrantes do Movimento na docência da educação infantil e dos anos iniciais do ensino fundamental nas escolas em questâo. Além disso, o governo tem repassado recursos insuficientes para garantir a melhoria e manutenção da estrutura física, não tem promovido processos de formação continuada que atendam às necessidades dessas escolas que, para serem mantidas em funcionamento, têm consumido parte dos esforços das equipes das escolas e do setor estadual de educaçáo do MST/PR. Isso indica claramente a posição do Estado diante das escolas do Movimento, diante da possibilidade de construção de propostas contra-hegemônicas.

Esse estado de coisas explicita que ainda há várias necessidades para a continuação do processo:

- a luta contra o desmonte das escolas itinerantes;

- a ampliação dos processos de formação continuada de todos os envolvidos;

- a cobrança para que o Estado assuma seu papel como mantenedor dessas escolas, uma vez que são escolas estaduais, mas preservando a autonomia pedagógica das mesmas;

- a ampliação dos processos de auto-organização e do próprio tempo escolar.

\section{Considerações finais}

A atual proposta educacional do MST/PR expressa o acúmulo que o Movimento realizou no processo de construção da mesma e um avanço importante da teoria pedagógica. A implementação dos ciclos de formação humana exigiu, num determinado momento, mais um salto qualitativo nesse processo e, portanto, o estudo aprofundado da pedagogia russa pós-revolução. Isso colocou o Movimento diante de um grande desafio: o de buscar cada vez mais na teoria marxista 
as bases para o processo de formaçáo humana que defende e busca consolidar em todos os espaços, dentre eles, a escola. Há, a partir disso, uma reafirmação do posicionamento da escola no interior da luta de classes.

O processo de construção e implementação da proposta dos ciclos de formaçáo humana com a incorporação dos complexos de estudo tem provocado um movimento na escolha de vários elementos que alteram sua forma e seu conteúdo:

- a organização do trabalho pedagógico a partir da vida e, em decorrência dela, das matrizes de trabalho, luta social, organizaçáo coletiva, história e cultura;

- práticas de auto-organização dos estudantes;

- $\quad$ concepção de educação como processo de formação humana;

- o acesso ao conhecimento de forma crítica;

- planejamento coletivo e alteração dos processos de gestáo escolar com a ampliação da participação.

Esse processo tem representado um importante exercício de autogestáo, o que encontramos em poucos espaços escolares e que exige uma tomada de consciência e um posicionamento de classe na perspectiva de construir processos de formação humana que almejam contribuir para a emancipação dos indivíduos. Também expressa um importante esforço no engendramento imediato da contra-hegemonia à escola capitalista, explicitada claramente a partir dos autores que aqui apresentamos e que, com certeza, realizar-se-á plenamente em uma sociedade diferente que tenha perspectiva de concretização da humanidade dos sujeitos.

O MST tem realizado, nesse caminho, a redefinição do papel da escola e o reposicionamento da questão curricular, orientado pelo entendimento de que não há neutralidade na educação e que a mesma é um ato político, de classe. Esse esforço tem sido feito no sentido de promover mudanças e não meras reformas na forma e no conteúdo escolar; porém, a materialidade das escolas, a precariedade dos contratos e das condiçôes de trabalho, a formação dos professores e a cultura enraizada na escola têm sido limitantes para o avanço dessa proposição.

A análise do processo em questão indica que é necessário construir e ampliar processos que potencializem o controle social da escola da classe trabalhadora pelos próprios trabalhadores, contrapondo-se ao controle estatal da mesma, orientado pelos princípios impostos pelo capital, especialmente sob a influência das agências internacionais e dos empresários, ou seja, a formação acrítica do tra- 
balhador, o desenvolvimento de habilidades e competências que atendam às exigências da produção capitalista, bem como a construção simbólica que naturalize tais processos. O controle social pelos trabalhadores, além de favorecer o exercício da autogestão, poderia ajudar a construir processos de formação crítica, política, de denúncia e de desvelamento da realidade na perspectiva da totalidade, o que representa importante instrumento de luta social.

\section{Notas}

1. Escolas itinerantes são escolas inseridas em acampamentos do MST e quando há mudança de local do acampamento, da ocupaçáo, a escola acompanha a mesma. Por isso, essas escolas são responsabilidade do governo do estado e não dos municípios e estáo vinculadas a uma escola base, o Colégio Estadual do Campo Iraci Salete Strozak (Rio Bonito do Iguaçu, PR), que é responsável pela orientação pedagógica e pela guarda dos documentos das referidas escolas (SAPELLI, 2013).

2. Para Marx (2006), a classe para si é uma necessidade para a revoluçáo, pois essa classe deveria ter consciência de si e deveria se constituir a partir de esferas radicais, que representasse a dissoluçáo de todas as classes, que tivesse caráter universal e que não exigisse reparação particular, que buscasse a redenção total do ser humano. Ou seja, Marx afirma que a emancipação humana, quando motivo da luta de classes, só poderia ser alcançada com o fim da existência das classes. Assim, entendemos, que a constituição de uma classe revolucionária, classe para si, é necessária para buscar não a mudança de posiçáo de classe, não a inversão do domínio entre as classes, mas o fim das classes.

3. Essa discussão foi apresentada originalmente em Sapelli (2013).

4. As informaçôes de Roseli Salete Caldart foram coletadas por meio de entrevista concedida à autora, em 30 de março de 2012.

5. As informaçóes de Luiz Carlos de Freitas foram coletadas por meio de entrevista concedida à autora, em 13 de outubro de 2011.

6. Contribuíram para a indicação das dificuldades, avanços e necessidades: Alessandro Santos Mariano (MST), Valter de Jesus Leite (MST), Gilson Gonçalves (Diretor do Colégio Estadual do Campo Aprendendo com a terra e com a vida; Cascavel, PR) e a equipe pedagógica da Escola Itinerante Herdeiros de Porecatu (Porecatu, PR).

\section{Referências}

ARROYO, M.G. As relações sociais na escola e a formação do trabalhador. In: FERRETTI, C.J.; SILVA JR., J.R.; OLIVEIRA, M.R.N.S. Trabalho, formação e currículo: para onde vai a escola? São Paulo: Xamã, 1999. 
BAHNIUK, Caroline. Experiências escolares e estratégia politica: da pedagogia socialista à atualidade do MST. 302 p. Tese (Doutorado) - Programa de Pós-Graduação em Educação, Universidade Federal de Santa Catarina, Florianópolis, 2015.

BOURDIEU, Pierre; PASSERON, Jean-Claude. A reprodução: elementos para uma teoria de ensino. Trad. Reynaldo Bairão. Petrópolis: Vozes, 2008.

GOVERNO DO PARANÁ. Secretaria de Estado da Educação. Projeto político-pedagógico do Colégio Estadual do Campo Iraci Salete Strozak. Rio Bonito do Iguaçu, 2009.

. Projeto político-pedagógico do Colégio Estadual do Campo Iraci Salete Strozak. Rio Bonito do Iguaçu, 2013.

KRUPSKAYA, N.K. A construção da pedagogia socialista. São Paulo: Expressão Popular, 2017.

LEITE, V.J. Educação do campo e ensaios da escola do trabalho: a materialização do trabalho como princípio educativo na escola itinerante do MST Paraná. 306 f. Dissertação (Mestrado em Educação) - Programa de Pós-Graduação em Educação, Universidade Estadual do Oeste do Paraná, Cascavel, 2017.

LOYOLA, M.A. Pierre Bourdieu. Rio de Janeiro: EdUERJ, 2002.

MARIANO, A.S. Ensaios da escola do trabalho no contexto das lutas do MST: a proposta curricular dos ciclos de formação humana com complexos de estudo, nas escolas itinerantes no Paraná. 255 p. Dissertação (Mestrado) - Programa de Pós-Graduação em Educação, Universidade Estadual do Centro Oeste do Paraná, Guarapuava, 2016.

MARX, K. Manuscritos econômico-filosóficos. Trad. Alex Martins. São Paulo: Martin Claret, 2006.

MÉSZÁROS, I. A educaçâo para além do capital. Trad. Isa Tavares. São Paulo: Boitempo, 2005.

MOVIMENTO DOS TRABALHADORES RURAIS SEM-TERRA (MST). Memória do processo de construçáo da proposta dos Complexos de Estudo. Curitiba, 2014. (mimeo.). . Plano de Estudos. Cascavel: Unioeste, 2013.

PISTRAK, M.M. (Org.). A Escola-comuna. Trad. Luiz Carlos de Freitas e Alexandra Marenich. São Paulo: Expressão Popular, 2009.

RITTER, J. Complexos de estudo: uma proposta para as Escolas Itinerantes do Paraná - limites e possibilidades. 253 p. Tese (Doutorado) - Programa de Pós-Graduação em Educação da Universidade Estadual de Campinas, Campinas, 2016.

SAPELLI, M.L.S. Escola do campo - Espaço de disputa e de contradição: análise da proposta pedagógica das Escolas Itinerantes do Paraná e do Colégio Imperatriz Dona Leopoldina. Tese (Doutorado) - Programa de Pós-Graduação em Educação da Universidade Federal de Santa Catarina, Florianópolis, 2013.

SAPELLI, M.L.S.; FREITAS, L.C. de; CALDART, R.S. Caminhos para a transformação da escola 3: organização do trabalho pedagógico nas escolas do campo - Ensaio sobre complexos de estudo. São Paulo: Expressão Popular, 2015.

SAVI, C.L. Complexos de estudo: investigando um experimento de currículo em uma escola de assentamento do MST no Paraná. 144 p. Dissertação (Mestrado) - Programa de PósGraduação em Educação, Universidade Estadual do Oeste do Paraná, Francisco Beltrão, 2014. 
SHULGIN, V.N. Rumo ao politecnismo. São Paulo: Expressão Popular, 2013.

SNYDERS, G. Escola, classe e luta de classes. Trad. Leila Prado. São Paulo: Centauro, 2005.

SUCHODOLSKI, B. Teoria marxista da educação II. Trad. José Magalhães. Lisboa: Estampa, 1976.

TRICHES, J. A internalização da agenda do capital em cursos de pedagogia de universidades federais (2006-2015). 400 p. Tese (Doutorado) - Programa de Pós-Graduação em Educação, Universidade Federal de Santa Catarina, Florianópolis, 2016.

VYGOTSKY, L.S. Formação social da mente. São Paulo: Martins Fonte, 2007.

WACHOVICZ, L.A. O método dialético da didática. 3. ed. Campinas: Papirus, 1995.

Recebido em 8 de junho de 2017.

Aceito em 15 de agosto de 2017. 